\title{
Microstructural Evolution of Nanoindented Ag/Si Thin-Film under Different Annealing Temperatures
}

\author{
Woei-Shyan Lee ${ }^{1, *}$, Tao-Hsing Chen ${ }^{2}$, Chi-Feng Lin $^{3}$ and Cheng-Lun $\mathrm{Wu}^{1}$ \\ ${ }^{1}$ Department of Mechanical Engineering, National Cheng Kung University, Tainan 701, Taiwan, R. O. China \\ ${ }^{2}$ Department of Mechanical Engineering, National Kaohsiung University of Applied Sciences, \\ Kaohsiung 807, Taiwan, R. O. China \\ ${ }^{3}$ National Center for High-Performance Computing, Hsin-Shi Tainan County 744, Taiwan, R. O. China
}

\begin{abstract}
The microstructural evolution of $\mathrm{Ag} / \mathrm{Si}$ thin-film system via nanoindentation and annealing is investigated. Ag films with a thickness of $500 \mathrm{~nm}$ are deposited on (100) silicon substrates. Nanoindentation is performed to a maximum depth of $800 \mathrm{~nm}$, and the indented specimens are then annealed at temperatures of $600^{\circ} \mathrm{C}, 700^{\circ} \mathrm{C}$ and $800^{\circ} \mathrm{C}$, respectively. In the as-deposited specimen, the indentation process results in a phase transformation from a diamond cubic structure to amorphous phase within the indented zone. Following annealing at $600^{\circ} \mathrm{C}$, the microstructure of the indented zone changes from a fully-amorphous state to a mixed amorphous/nanocrystalline state. The diffusion ability of the Ag atoms into the silicon substrate is enhanced as the annealing temperature is increased. Consequently, the microstructures of the indentation zones in the specimens annealed at $700^{\circ} \mathrm{C}$ and $800^{\circ} \mathrm{C}$, respectively, contain a mixture of amorphous phase, nanocrystalline structures and $\mathrm{Ag}_{2} \mathrm{Si}$ silicide phase. Overall, the results presented in this study confirm that the annealing temperature has a significant effect on the formation of $\mathrm{Ag}_{2} \mathrm{Si}$ silicide phase in nanoindented Ag/Si thin-film systems. [doi:10.2320/matertrans.M2011160]
\end{abstract}

(Received May 31, 2011; Accepted July 29, 2011; Published September 14, 2011)

Keywords: nanoindentation, $\mathrm{Ag} / \mathrm{Si}$ thin film, annealing, $\mathrm{Ag}_{2}$ Si silicide phase, diffusion, amorphous

\section{Introduction}

Silicon is one of the most commonly used substrate materials in the microelectronics and optoelectronics industry due to its excellent semiconducting properties. Facecentered cubic (fcc) films deposited on silicon substrates are widely used as metallic contacts at the micro- and macroscales. ${ }^{1-3)}$ Depending on the particular application, the thinfilm system can range from very soft to ultra hard in comparison with the silicon substrate. The mechanical properties of thin-film materials are typically very different from those of the corresponding bulk materials. ${ }^{4,5)}$ As a result, accurate methods are required for their characterisation. The hardness and Young's modulus properties of thin-film systems are commonly evaluated using a nanoindentation technique, in which an indenter is driven to a predetermined depth within the system, held at this depth for a given period of time, and then withdrawn at a steady rate. ${ }^{6,7)}$ The loading curve obtained during the nanoindentation process often exhibits a discontinuity referred to as a "popin" event, ${ }^{8)}$ while the unloading curve sometimes contains a discontinuity referred to as a "pop-out" event. ${ }^{9)}$ Generally speaking, both events are indicative of a change in the phase transformation mechanism under the corresponding indentation load.

Previous studies have examined the microstructural transformation within the nanoindentation zone of thin-film systems by means of Raman spectroscopy, ${ }^{10)}$ scanning/ atomic force microscopy, ${ }^{11)}$ and transmission electron microscopy (TEM) using either plane-view ${ }^{12)}$ or cross-sectional $^{13)}$ specimens. In general, the results have shown that the plastic deformation and phase transformation induced during the nanoindentation of thin films are temperature

*Corresponding author, E-mail: wslee@mail.ncku.edu.tw dependent. Furthermore, it has been shown that the indented microstructure of an as-deposited specimen can be modified via annealing at a suitable temperature. ${ }^{14,15)}$ Furthermore, for thin films deposited on a silicon substrate, various types of silicide are commonly formed at the film/substrate interface during subsequent annealing. ${ }^{16)}$ Therefore, in developing thin film systems for device applications, a thorough understanding of the nanoindentation behaviour and microstructural evolution of thin film structures during nanoindentation and annealing is required.

Amongst all the face-centred cubic (fcc) materials, e.g., silver (Ag), gold ( $\mathrm{Au})$, nickel (Ni), and so on, $\mathrm{Ag}$ is one of the most commonly used for the coating of silicon substrates in the fabrication of electronic devices due to its low cost and excellent electronic, physical and chemical properties. ${ }^{17,18)}$ As a result, the fundamental properties of $\mathrm{Ag} / \mathrm{Si}$ systems and the nanoindentation response and microstructural evolution of $\mathrm{Ag} / \mathrm{Si}$ thin films have attracted increasing attention in recent years. Furthermore, various physical and chemical bonding methods have been proposed for fabricating $\mathrm{Ag} / \mathrm{Si}$ systems with coherent layers. ${ }^{19-22)}$ Although the nanoindentation properties of $\mathrm{Ag} / \mathrm{Si}$ thin films and the characteristics of $\mathrm{Ag} / \mathrm{Si}$ silicides compound have been studied, ${ }^{16,23)}$ the combined effects of nanoindentation deformation and annealing on the microstructural evolution and the formation of silicides phase of $\mathrm{Ag} / \mathrm{Si}$ thin films are not yet fully understood. Accordingly, this study uses a nanoindentation technique to examine the nano-mechanical properties of asdeposited $\mathrm{Ag} / \mathrm{Si}$ thin films indented to a depth of $800 \mathrm{~nm}$. The effects of the annealing temperature on the microstructural evolution and formation of $\mathrm{Ag}_{2} \mathrm{Si}$ silicide phase within the nanoindented specimens are then examined using transmission electron microscopy (TEM) and X-ray Diffractometer (XRD). 


\section{Experimental Procedure}

Polycrystalline Ag films with a thickness of $500 \mathrm{~nm}$ were deposited on $\mathrm{Si}$ (100) wafers. Prior to the deposition process, the wafers were cleaned in a $4: 1$ solution of sulfuric acid and hydrogen peroxide. The Ag films were deposited using a thermal evaporation technique under high vacuum conditions $\left(1.3 \times 10^{-4} \mathrm{~Pa}\right)$. During the deposition process, the substrate was maintained at a temperature of $150^{\circ} \mathrm{C}$ in order to enhance the evaporation process and improve the uniformity of the $\mathrm{Ag}$ film. The thickness of the Ag film was monitored continuously throughout the deposition process using a quartzcrystal microbalance and was verified via X-ray reflectometry once the fabrication process was complete.

The nanoindentation tests were performed at room temperature using an MTS Nano Indenter-XP system with a Berkovich diamond pyramid tip. The specimens were indented to a maximum depth of $800 \mathrm{~nm}$ using the indenter system set in a depth-control mode. The indentation procedure involved the following steps: (1) loading to the maximum indentation depth at a constant rate of $0.2 \mathrm{mN} / \mathrm{s}$, (2) holding at this depth for $10 \mathrm{~s}$, and (3) smoothly unloading over a period of $30 \mathrm{~s}$. The hardness and Young's modulus of the as-deposited $\mathrm{Ag} / \mathrm{Si}$ thin film were then calculated from the loading-unloading curve using the Oliver and Pharr method. ${ }^{6}$

Following the nanoindentation tests, selected specimens were annealed at temperatures of $600^{\circ} \mathrm{C}, 700^{\circ} \mathrm{C}$ or $800^{\circ} \mathrm{C}$ for $2 \mathrm{~min}$ in a rapid thermal annealing (RTA) furnace. During the annealing process, purified nitrogen gas $(99.999 \%)$ was flowed through the furnace at a flow rate of $31 \mathrm{~min}^{-1}$. The heating rate of the RTA furnace was maintained at $200^{\circ} \mathrm{C} \mathrm{s}^{-1}$, the cooling rate was approximately $5^{\circ} \mathrm{C} \mathrm{s}^{-1}$, and the recorded temperature measurements were accurate to $\pm 5^{\circ} \mathrm{C}$.

Thin foil specimens for TEM observations were prepared from the as-deposited and annealed samples using an FEI Nova 200 focused ion beam (FIB) system with an operating voltage of $30 \mathrm{keV}$. During the preparation process, the FIB chamber was maintained at a constant pressure of $1.3 \times$ $10^{-4} \sim 1.3 \times 10^{-5} \mathrm{~Pa}$ using a hybrid pumping system comprising a mechanical pump and an oil diffusion pump. The TEM foils were milled from the thin-film specimens using a $\mathrm{Ga}^{+}$ion beam and were extracted in such a way that they contained the centre of the indentation zone. (Note that before the foils were removed, a thin Pt film (thickness: $1 \mu \mathrm{m}$ ) was deposited on the specimen surface to protect the indentation region from accidental damage by the ion beam.)

The TEM specimens were placed on a copper net using a vitreous needle and were held in place via van der Waals forces. The copper net was placed in the TEM chamber and the microstructure of the indentation region was observed using a Philips Tecnai F30 electron microscope. During the observation process, the pressure in the TEM chamber was maintained at a constant $1.3 \times 10^{-6} \sim 1.3 \times 10^{-8} \mathrm{~Pa}$ by means of an ion pump, a turbo pump, a rotation pump and an oil diffusion pump. The chemical compounds observed at various positions of the as-deposited and annealed samples were identified using an EDAX energy dispersive X-ray spectrometer. Finally, the nature of the Ag silicide phase formed within the indented zone under each annealing
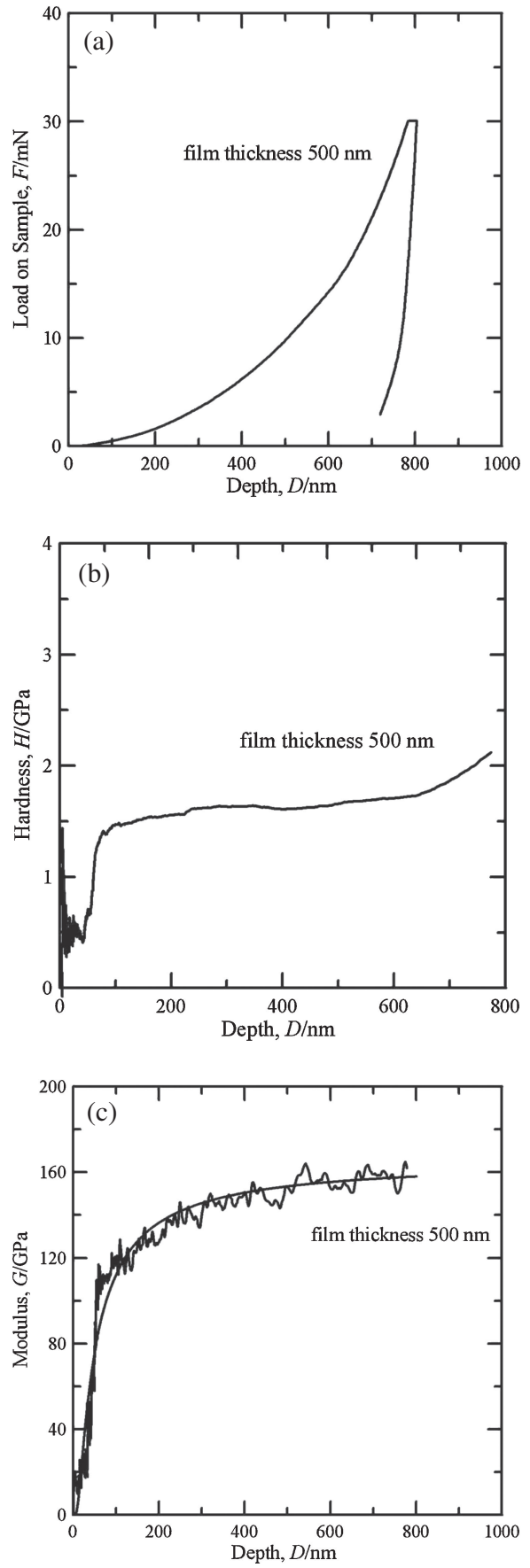

Fig. 1 (a) Loading-unloading curve obtained during nanoindentation of asdeposited $\mathrm{Ag} / \mathrm{Si}$ thin film; (b) variation of hardness of $\mathrm{Ag} / \mathrm{Si}$ thin film with indentation depth; (c) variation of Young's modulus of $\mathrm{Ag} / \mathrm{Si}$ thin film with indentation depth.

temperature is identified using a computer-controlled X-ray Diffraction system (PW 3040/60).

\section{Results and Discussion}

\subsection{Loading-unloading curve}

Figure 1(a) shows the loading-unloading curve of the asdeposited $\mathrm{Ag} / \mathrm{Si}$ thin film. It can be seen that the loading part of the curve is continuous and smooth without any pop-in event. For indentation depths of less than $50 \mathrm{~nm}$, the indenter tip is fully enclosed within the Ag film. The film has a low 
hardness and is easily deformed, and thus the load is very small and remains virtually constant. However as the indentation depth is increased, the indenter penetrates through the Ag layer and enters the underlying, harder Si substrate. As a result, the load increases rapidly toward a maximum value of $28.5 \mathrm{mN}$ at the maximum indentation depth of $800 \mathrm{~nm}$. This value is less than the critical load of $30 \mathrm{mN}$ associated with the pop-out event for hard $\mathrm{Si}$ substrates. ${ }^{24)}$ As a result, the unloading portion of the curve in Fig. 1(a) has a smooth gradient. The almost vertical slope of the unloading curve indicates that the plastic deformation which occurs during the loading process is followed by a very weak elastic return in the unloading step. Moreover, the presence of a slight elbow feature in the final portion of the unloading curve suggests that the silicon substrate transforms from a diamond cubic like structure to an amorphous structure in the indentation affected zone. (Note that this inference is consistent with the findings presented ${ }^{9,25)}$ for silicon subjected to indentation loading). Furthermore, the inference is also supported by the evidence provided by Raman spectroscopy of the phase transformation within residual indents. ${ }^{9,26,27)}$

\subsection{Hardness and Young's modulus curves}

Figure 1(b) shows the variation of the hardness of the asdeposited $\mathrm{Ag} / \mathrm{Si}$ thin film with the nanoindentation depth. During the initial indentation stage (i.e., nanoindentation depths of less than $50 \mathrm{~nm}$ ), the hardness oscillates between $0.4 \mathrm{GPa}$ and $1.4 \mathrm{GPa}$. The oscillation in the hardness value is caused by the indentation size effect ${ }^{28)}$ and a poorlycalibrated tip area function. ${ }^{29)}$ At indentation depths greater than $50 \mathrm{~nm}$, the indenter penetrates more deeply into the $\mathrm{Ag}$ layer, and the hardness increases rapidly to a value of approximately $1.5 \mathrm{GPa}$ at an indentation depth of $100 \mathrm{~nm}$. Thereafter, the hardness increases slightly to a value of approximately $1.6 \mathrm{GPa}$ and remains approximately constant until an indentation depth of around $600 \mathrm{~nm}$. As the indentation depth is increased beyond this point, the hardness increases linearly as a result of the substrate effect. At the maximum indentation depth of $800 \mathrm{~nm}$, the hardness has a value of approximately $2.1 \mathrm{GPa}$. The measured hardness value of $1.6 \mathrm{GPa}$ at an indentation depth of $500 \mathrm{~nm}$ is in good agreement with the value of $1.57 \sim 1.63 \mathrm{GPa}$ reported $^{30)}$ for $\mathrm{Ag}$ films with thicknesses of $500 \sim 1000 \mathrm{~nm}$ deposited on $\mathrm{Si}$ substrates. Furthermore, it is noted that the hardness value of $1.6 \mathrm{GPa}$ measured at indentation depths of $100 \sim 600 \mathrm{~nm}$ is higher than that of bulk silver single crystal $(0.42 \pm$ $0.03 \mathrm{GPa}),{ }^{31)}$ but lower than that of an uncoated Si (100) substrate $(12.8 \mathrm{GPa}){ }^{32)}$

Figure 1(c) shows the variation of the Young's modulus of the as-deposited $\mathrm{Ag} / \mathrm{Si}$ thin film with the nanoindentation depth. For indentation depths of less than $10 \mathrm{~nm}$, the Young's modulus has a value of approximately $20 \mathrm{GPa}$. However, as the indenter penetrates more deeply into the Ag film, the Young's modulus decreases to a value of around $10 \mathrm{GPa}$. As with the hardness results presented in Fig. 1(b), the variation of the Young's modulus at very low indentation depths is caused by the indentation size effect and a poorly-calibrated tip area function. As the indentation depth is increased beyond $50 \mathrm{~nm}$, the Young's modulus increases rapidly to a
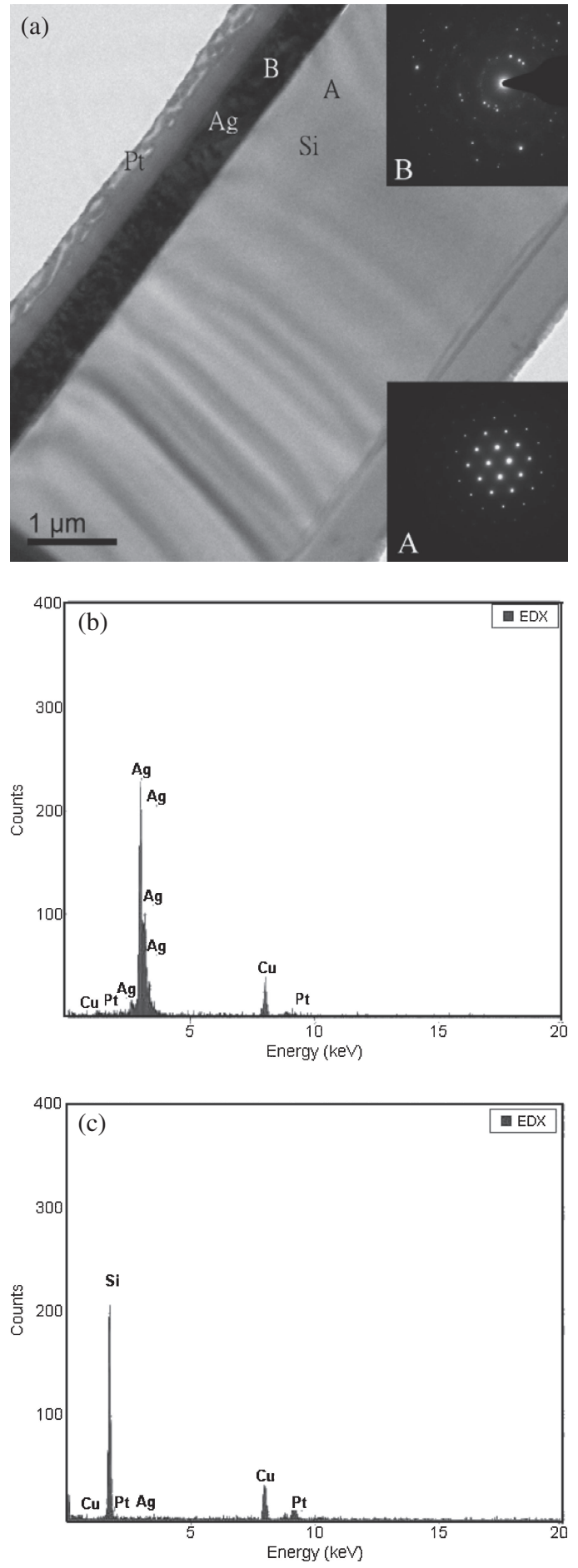

Fig. 2 (a) Bright field TEM micrograph of as-deposited $\mathrm{Ag} / \mathrm{Si}$ thin-film; (b) EDX analysis results for Ag thin film; (c) EDX analysis results for $\mathrm{Si}$ substrate.

value of around $110 \mathrm{GPa}$ at an indentation depth of $100 \mathrm{~nm}$ and then increases more slowly toward a maximum value of $158 \mathrm{GPa}$ at the maximum indentation depth of $800 \mathrm{~nm}$. It is noted that the value of $158 \mathrm{GPa}$ is lower than that of an uncoated Si (100) substrate (i.e., $169.0 \mathrm{GPa})^{32}$ ) due to the presence of the Ag layer. However, the Young's modulus of the $\mathrm{Ag} / \mathrm{Si}$ system is significantly higher than that of (100) oriented bulk Ag single crystal (i.e., $\left.E_{100}=124 \mathrm{GPa}\right)^{33)}$ as a result of the substrate effect. 


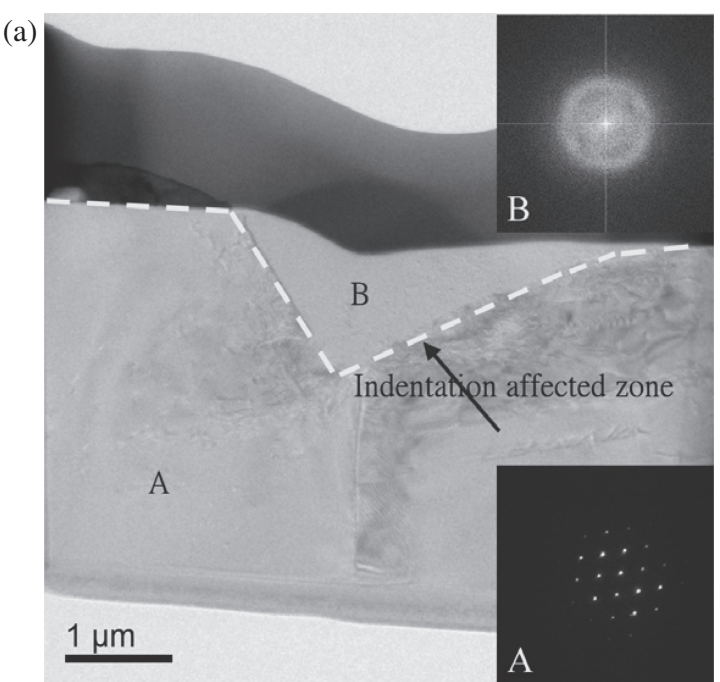

(b)

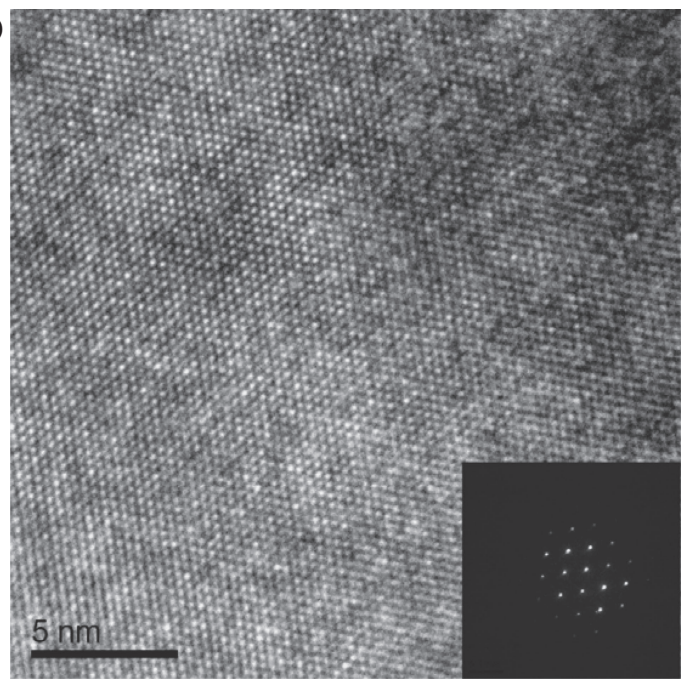

(c)
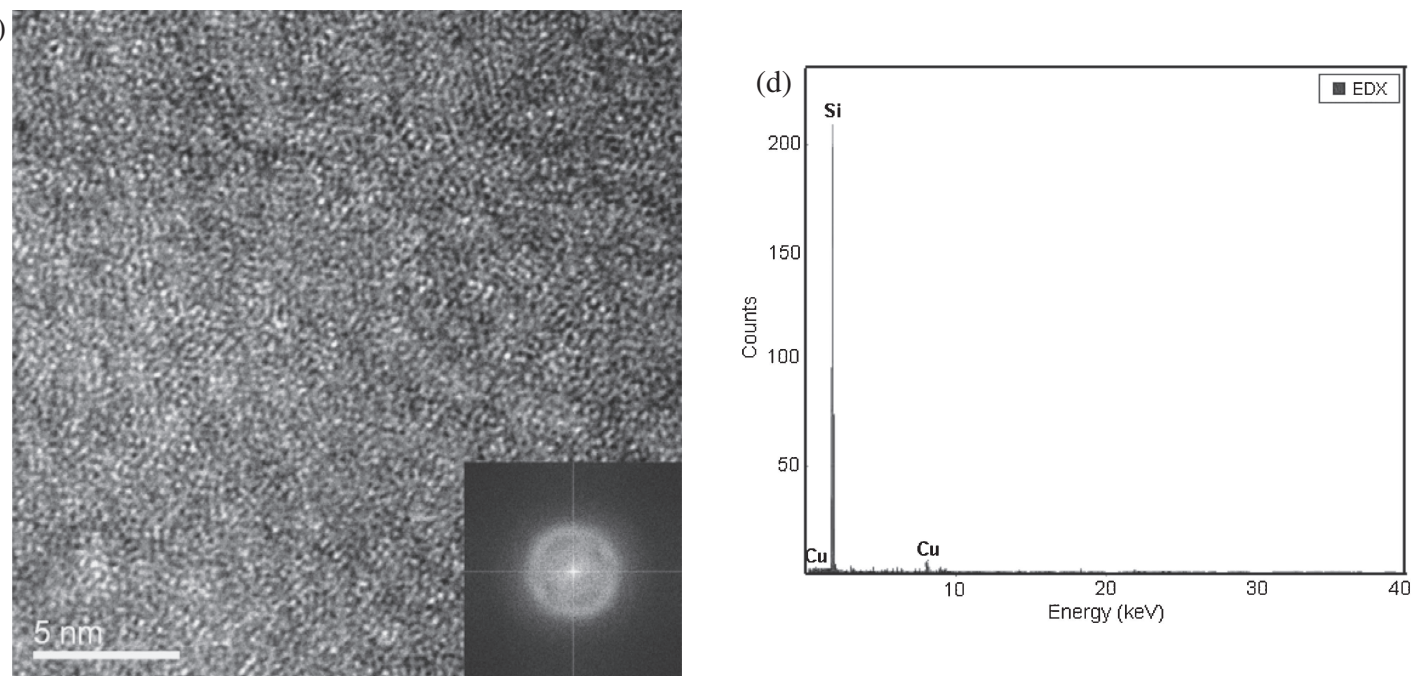

Fig. 3 (a) Bright field TEM micrograph of as-deposited indented specimen; (b) high-magnification micrograph of Si substrate; (c) highmagnification micrograph of indentation affected zone; (d) EDX analysis results for Fig. 3(c).

\subsection{Initial and indented microstructures of as-deposited $\mathrm{Ag} / \mathrm{Si}$ thin films}

Figure 2(a) presents a TEM micrograph of the as-deposited $\mathrm{Ag} / \mathrm{Si}$ thin film prior to indentation. A well-defined boundary is observed between the $\mathrm{Ag}$ film and the $\mathrm{Si}$ substrate. As shown in the selected area diffraction (SAD) patterns in the upper-right and lower-right corners of Fig. 2(a), the Ag thin film (B) has a polycrystalline structure while the silicon substrate (A) has a single crystal structure. The EDX analysis results for the Ag thin film and silicon substrate are presented in Figs. 2(b) and 2(c), respectively.

Figure 3(a) presents a cross-sectional TEM micrograph of the as-deposited $\mathrm{Ag} / \mathrm{Si}$ specimen indented to $800 \mathrm{~nm}$. The insets in the lower-right and upper-right corners of the figure show the TEM diffraction patterns of regions $\mathrm{A}$ and $\mathrm{B}$, respectively. The results show that the silicon substrate has a diamond cubic structure while the indentation affected zone comprises amorphous phase. Figure 3(b) shows a highresolution TEM micrograph of the silicon substrate. Similarly, Fig. 3(c) presents a high-resolution TEM micrograph of the indentation affected zone. As discussed in Section 3.1, the change from a diamond cubic structure to fullyamorphous phase in the indentation affected zone is thought to account for the elbow feature observed in the final portion of the unloading curve obtained in the nanoindentation test. The EDX analysis results for the indentation affected zone are presented in Fig. 3(d).

\subsection{Indented microstructure following annealing at different temperatures}

Figure 4(a) presents a cross-sectional TEM micrograph of the indented $\mathrm{Ag} / \mathrm{Si}$ specimen annealed at a temperature of $600^{\circ} \mathrm{C}$. The insets in the lower-left and upper-right corners of the figure show the TEM diffraction patterns of the silicon substrate (A) and indentation affected zone (B), respectively. Figure 4(b) shows that the silicon substrate retains a diamond cubic structure following the annealing process. However, as shown in Fig. 4(c), the annealing temperature causes the microstructure in the indentation affected zone to change from a fully-amorphous state to a mixed amorphous/nanocrystalline state. Figure 4(d) shows the EDX analysis results for the indentation affected zone (B). The silicide phase does 
(a)

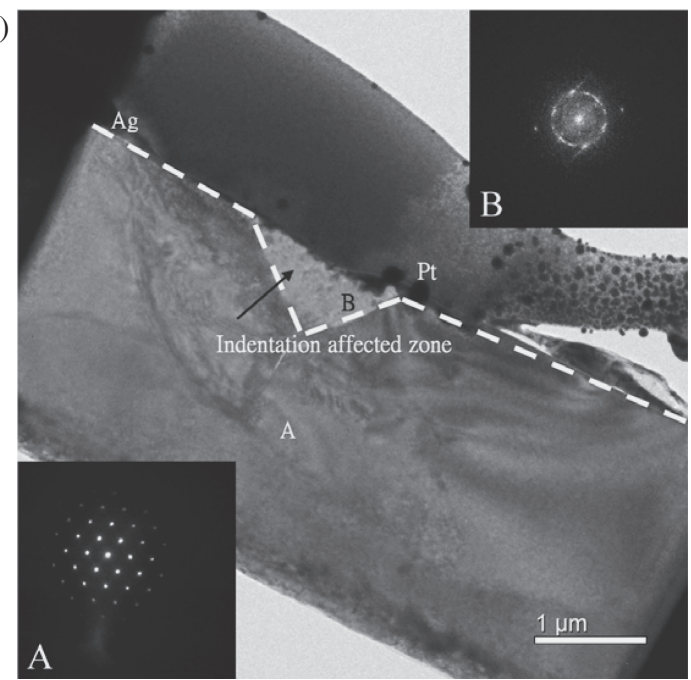

(c)

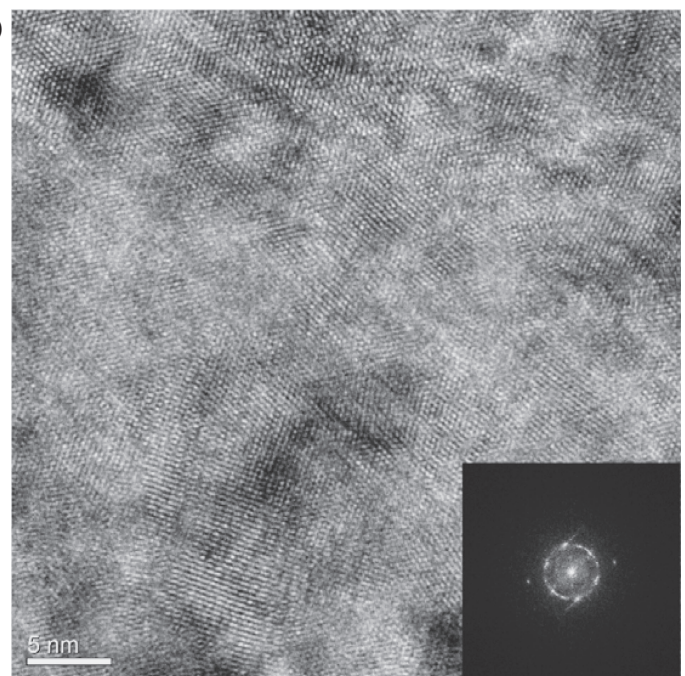

(b)
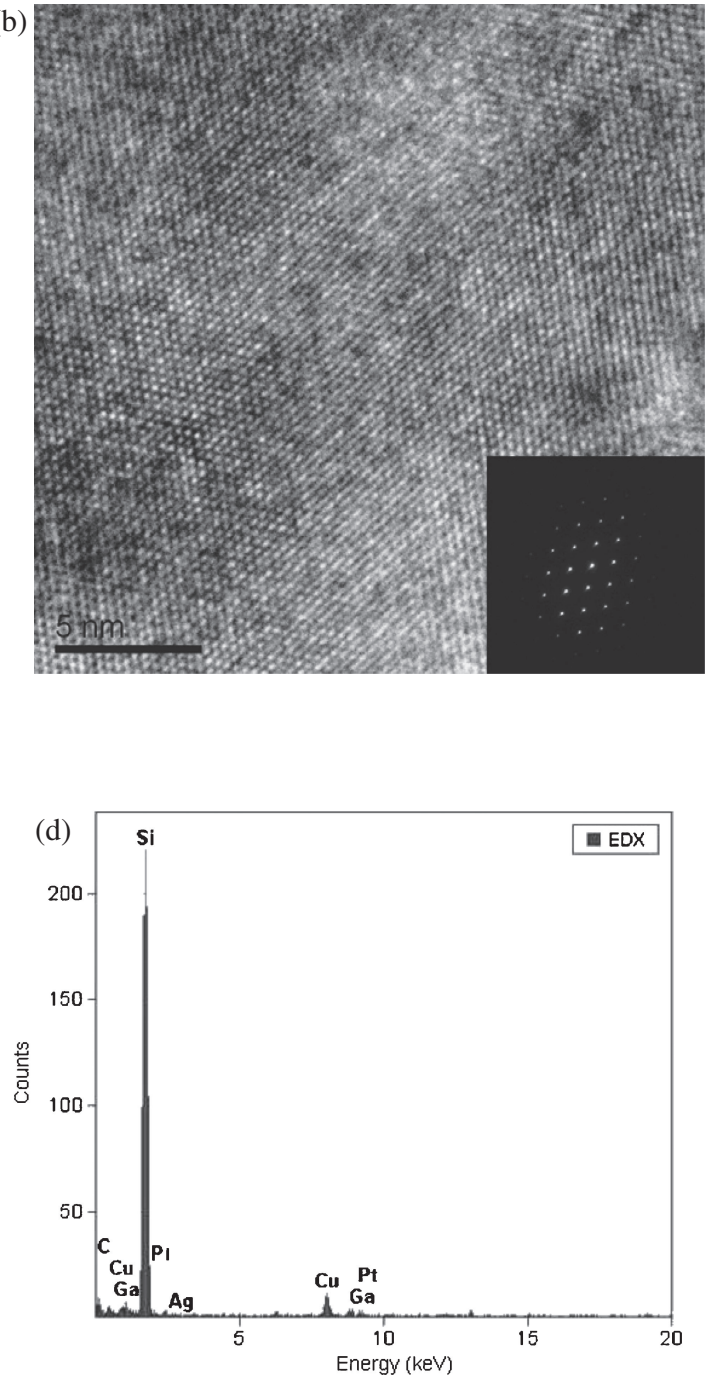

Fig. 4 (a) Bright field TEM micrograph of indented specimen annealed at $600^{\circ} \mathrm{C}$ for 2 min; (b) high-magnification micrograph of Si substrate; (c) high-magnification micrograph of indentation affected zone; (d) EDX analysis results for Fig. 4(c).

not form at lower annealing temperature of $600^{\circ} \mathrm{C}$, implying that the diffusion activity between $\mathrm{Ag}$ atoms and silicon substrate is in sufficient.

Figure 5(a) presents a TEM micrograph of the indented $\mathrm{Ag} / \mathrm{Si}$ specimen annealed at $700^{\circ} \mathrm{C}$. In contrast to the asdeposited indented specimens and the specimens annealed at temperature of $600^{\circ} \mathrm{C}$, the current specimen contains $\mathrm{Ag}_{2} \mathrm{Si}$ silicide phase in the indentation affected zone. The highmagnification TEM micrograph presented in Fig. 5(b) shows that the silicon substrate retains a diamond cubic structure. However, the elevated annealing temperature causes the reconstruction of $\mathrm{Si}$ either the $\mathrm{Si}$ atom diffuse into the $\mathrm{Ag}$ layer or diffusion of $\mathrm{Ag}$ into the Si layer to form silver silicide compounds. Thus, as shown in Fig. 5(c), corresponding to region $\mathrm{C}$ in Fig. 5(a), the indentation affected zone contains $\mathrm{Ag}_{2} \mathrm{Si}$ silicide phase with a crystalline structure. Note that $\mathrm{Ag}_{2} \mathrm{Si}$ silicide phase has an orthorhombic structure, with lattice parameters $a=0.566 \mathrm{~nm}, b=0.916 \mathrm{~nm}, c=$ $0.849 \mathrm{~nm}^{34)}$ In addition, it can be seen that the matrix microstructure around the $\mathrm{Ag}_{2} \mathrm{Si}$ silicide phase contains a mixture of amorphous phase and nanocrystalline phase. The EDX analysis results for the indentation affected zone are presented in Fig. 5(d). The XRD measurement within the indentation affected zone confirms the presence of silicide compound and their crystallinity. The XRD spectra of the asdeposited indented specimen and the indented specimens annealed at temperatures of $600^{\circ} \mathrm{C}, 700^{\circ} \mathrm{C}$, and $800^{\circ} \mathrm{C}$ are shown in Fig. 5(e). As observed, $\mathrm{Ag}_{2} \mathrm{Si}, \mathrm{Ag}$ and $\mathrm{Si}$ peaks are formed at $32.31^{\circ}, 38^{\circ}$ and $70^{\circ}$, respectively. Similar results are reported by Saliana et al. ${ }^{35)}$

Figure 6(a) presents a TEM micrograph of the indented $\mathrm{Ag} / \mathrm{Si}$ specimen annealed at a temperature of $800^{\circ} \mathrm{C}$. Figure 6(b) shows that the silicon substrate (indicated by the white square A in Fig. 6(a)) still has a diamond cubic structure. However, Figs. 6(c) and 6(d), corresponding to regions $\mathrm{B}$ and $\mathrm{C}$ in Fig. 6(a), respectively, show that the indentation affected zone contains a mixture of amorphous phase, nanocrystalline phase and $\mathrm{Ag}_{2} \mathrm{Si}$ silicide phase. It is emphasized that in Fig. 6(a), the region of $\mathrm{Si}$ substrate (labeled $\mathrm{A}$ ) and the regions of $\mathrm{Ag}_{2} \mathrm{Si}$ silicide phase (labeled 
(a)

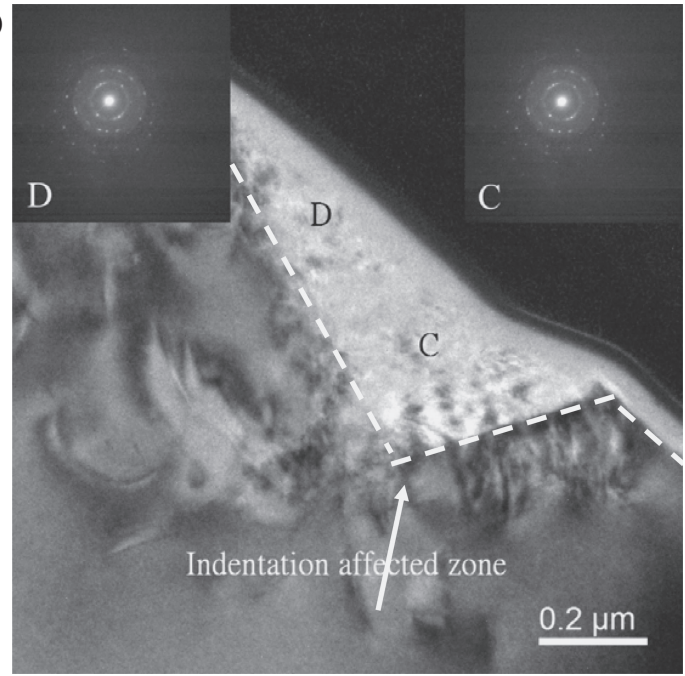

(c)
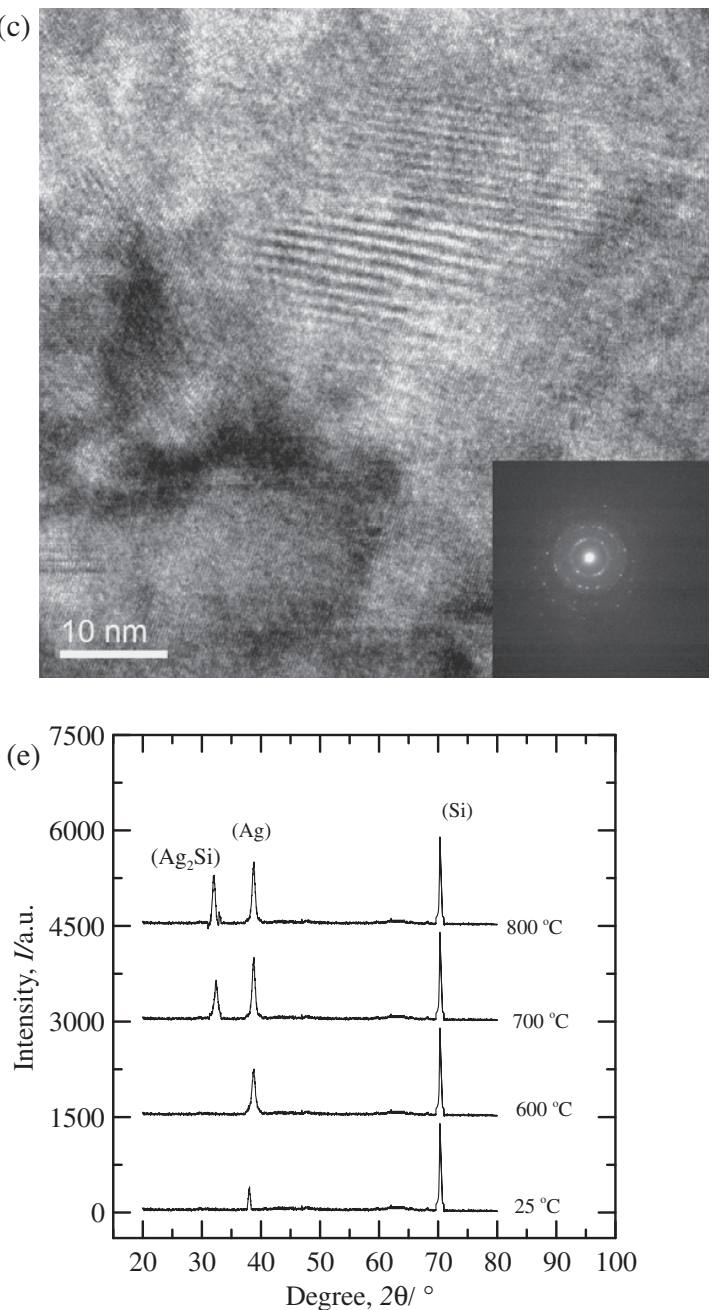

(b)

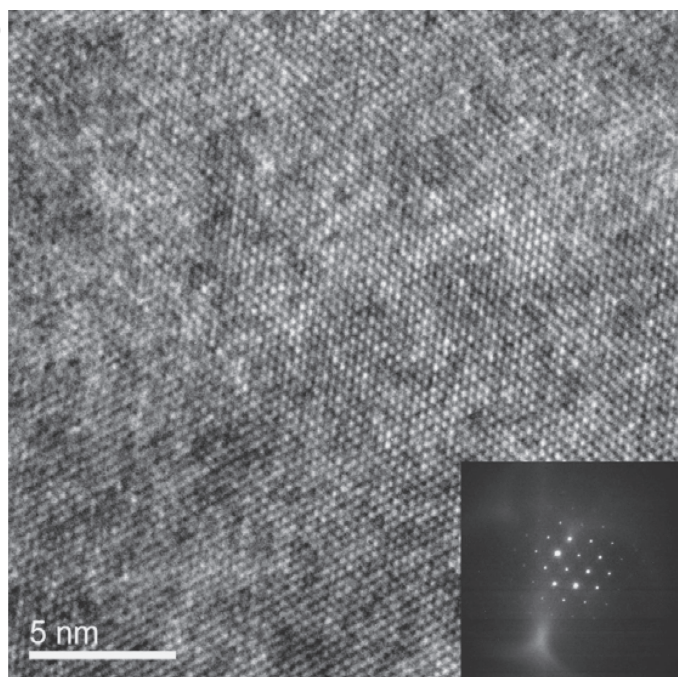

(d)

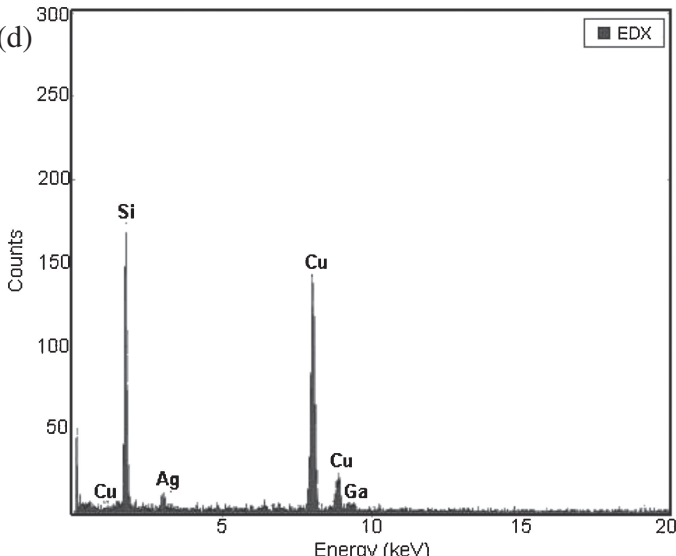

Fig. 5 (a) Bright field TEM micrograph of indented specimen annealed at $700^{\circ} \mathrm{C}$ for 2 min; (b) high-magnification micrograph of Si substrate; (c) high-magnification micrograph of indentation affected zone; (d) EDX analysis results for Fig. 5(c); (e) X-ray diffraction spectra of $\mathrm{Ag} / \mathrm{Si}$ thin film at $25^{\circ} \mathrm{C}$ and various annealing temperatures ranging from $600^{\circ} \mathrm{C} \sim 800^{\circ} \mathrm{C}$.

B and C) have the same distance from the silver layer. The peak of silver silicide becomes significantly stronger and sharper with increasing of annealing temperature as shown in Fig. 5(e). The intensity of the $\mathrm{Ag}_{2} \mathrm{Si}$ silicide phase increases with increasing the annealing temperature due to the greater diffusion ability of the $\mathrm{Ag}$ atoms. As a result, the indentation affected zone contains a greater amount of $\mathrm{Ag}_{2} \mathrm{Si}$ silicide phase than that in the specimen annealed at a lower temperature of $700^{\circ} \mathrm{C}$. The increased presence of $\mathrm{Ag}_{2} \mathrm{Si}$ silicide phase within the indentaion affected zone can be 
(a)

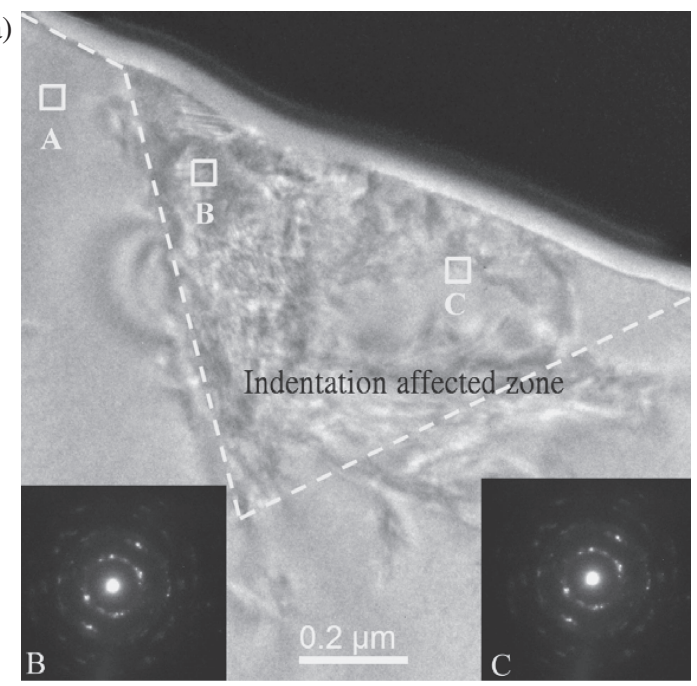

(c)
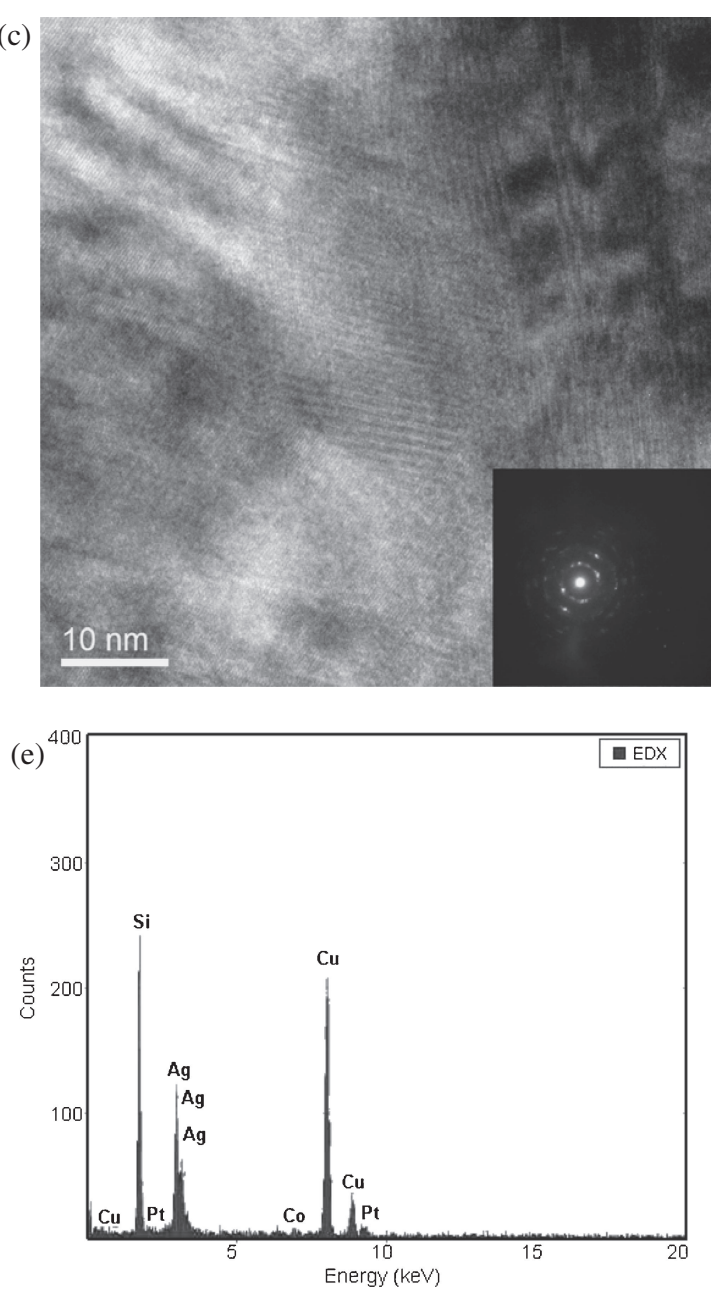

(b)

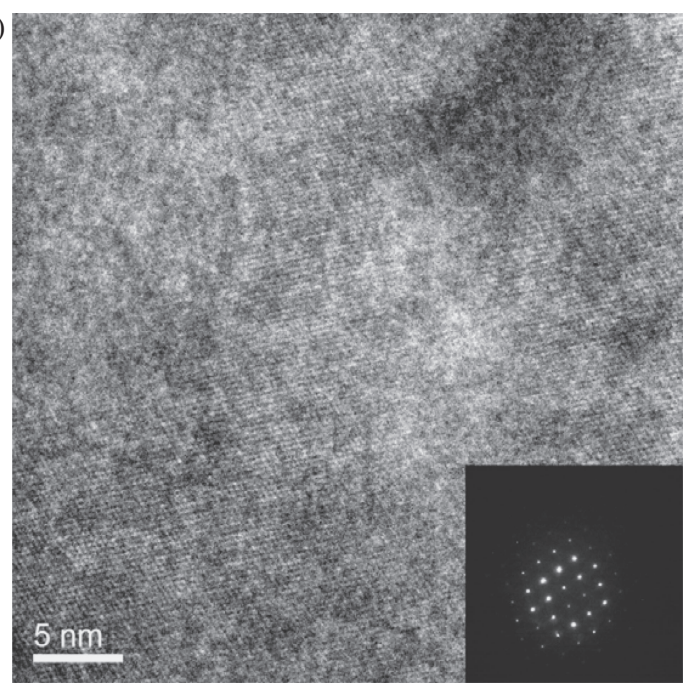

(d)

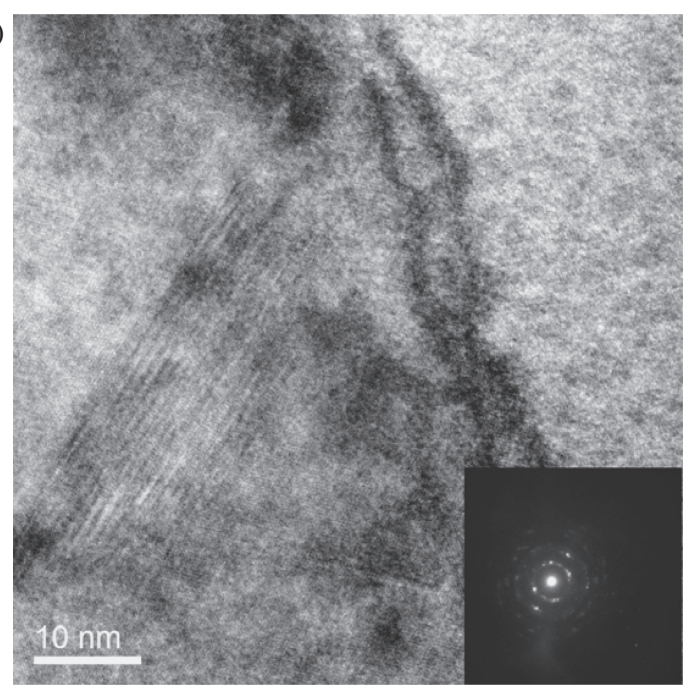

Fig. 6 (a) Bright field TEM micrograph of indented specimen annealed at $800^{\circ} \mathrm{C}$ for 2 min; (b) high-magnification micrograph of Si substrate; (c) high-magnification micrograph of region B in Fig. 6(a); (d) high-magnification micrograph of region C in Fig. 6(a); (e) EDX analysis results for eutectic phase within indentation affected zone.

attributed to the stronger diffusion effect induced by the higher temperature. The annealing processes and diffusion activity can be explained by the classical Arrhenius equation. ${ }^{36)}$ The diffusion activity and diffusion reaction rate of the $\mathrm{Ag}$ atoms into the $\mathrm{Si}$ substrate both increase with increasing annealing temperature. The present study has shown that the formation of $\mathrm{Ag}_{2} \mathrm{Si}$ silicide phase can also be induced by nanoindenting the Ag-Si system and then annealing the indented microstructure at a temperature of $700^{\circ} \mathrm{C}$ (or above). This phenomenon can be explained by the fact that nanoindentation causes a significant distortion of the lattice structure within the indented zone. During annealing, 
the distorted crystalline structure results in an increased number of diffusion paths between the $\mathrm{Ag}$ layer and the $\mathrm{Si}$ substrate. Consequently, the diffusivity of the $\mathrm{Ag}$ atoms is enhanced, and crystallisation of $\mathrm{Ag}_{2} \mathrm{Si}$ silicide phase occurs.

\section{Conclusion}

The effect of the annealing temperature $\left(600^{\circ} \mathrm{C} \sim 800^{\circ} \mathrm{C}\right)$ on the formation of $\mathrm{Ag}-\mathrm{Si}$ eutectic phase in the indentation affected zone of $\mathrm{Ag} / \mathrm{Si}$ thin-film systems has been examined. The results have shown that in the as-deposited specimen, the indentation process results in a phase transformation from a diamond cubic structure to fully-amorphous phase. Moreover, it has been shown that the hardness and Young's modulus of the as-deposited $\mathrm{Ag} / \mathrm{Si}$ system are equal to $2.1 \mathrm{GPa}$ and $158 \mathrm{GPa}$, respectively, at the maximum indentation depth of $800 \mathrm{~nm}$. The TEM observations have revealed that the annealing process induces a significant microstructural change within the indentation affected zone. For all three annealing temperatures, i.e., $600^{\circ} \mathrm{C}, 700^{\circ} \mathrm{C}$ and $800^{\circ} \mathrm{C}$, the microstructure within the indentation zone is characterised by a mixed amorphous phase/nanocrystalline structure. In addition, for the specimens annealed at a temperature of $700^{\circ} \mathrm{C}$ or more, the indentation zone also contains $\mathrm{Ag}_{2} \mathrm{Si}$ silicide phase. The intensity of the $\mathrm{Ag}_{2} \mathrm{Si}$ silicide phase increases with an increasing annealing temperature due to the greater diffusivity of the $\mathrm{Ag}$ atoms into the silicon substrate. Thus, the amount of $\mathrm{Ag}_{2} \mathrm{Si}$ silicide phase increases with an increasing annealing temperature.

\section{Acknowledgements}

The authors gratefully acknowledge the financial support provided to this study by the National Science Council (NSC) of Taiwan under Contract No. NSC 98-2221-E006-035.

\section{REFERENCES}

1) S. Majumder, N. E. McGruer, G. G. Adams, P. M. Zavracky, R. H. Morrison and J. Krim: Sens. Actuator A-Phys. 93 (2001) 19-26.

2) J. Plummer, M. Deal and P. Griffin: Silicon VLSI Technology: Fundamentals, practice and modeling, (Prentice Hall, Upper Saddle River, NJ, 2000).

3) Y. Cao, C. Kim, S. R. Forrest and W. O. Soboyejo: J. Appl. Phys. 98 (2005) 033713-1

4) R. Saha and W. D. Nix: Acta Mater. 50 (2002) 23-28.

5) J. Lou, P. Shrotriya, T. Buchheit, D. Yang and W. O. Soboyejo: J. Mater. Res. 18 (2003) 719-728.

6) W. C. Oliver and G. M. Pharr: J. Mater. Res. 7 (1992) 1564-1583.

7) T. Chudoba, N. Schwarzer and F. Richter: Surf. Coat. Technol. 127
(2000) 9-17.

8) J. E. Bradby, J. S. Williams, J. Wong-Leung, M. V. Swain and P. Munroe: J. Mater. Res. 16 (2001) 1500-1507.

9) V. Domnich and Y. Gogotsi: Rev. Adv. Mater. Sci. 3 (2002) 1-36.

10) Y. Gogotsi, C. Baek and F. Kirscht: Semicond. Sci. Technol. 14 (1999) 936-944.

11) J. Yan, H. Takahashi, J. Tamaki, X. Gai, H. Harada and J. Patten: Appl. Phys. Lett. 86 (2005) 181913.

12) G. Patriarche, E. Le Bourhis, D. Faurie and P. O. Renault: Thin Solid Films 460 (2004) 150-155.

13) L. Zhang and I. Zarudi: Int. J. Mech. Sci. 43 (2001) 1985-1996.

14) H. S. Chou, J. C. Huang, L. W. Chang and T. G. Nieh: Appl. Phys. Lett. 93 (2008) 191901.

15) A. A. Volimsky, N. R. Moody and W. W. Gerberich: J. Mater. Res. 19 (2004) 2650-2657.

16) D. K. Sarker, S. Dhara, K. G. M. Nair and S. Chowdhury: Nucl. Instrum. Meth. B 168 (2000) 215-220.

17) M. V. ten Kortenaar, J. J. M. de Goeij, Z. I. Kolar, G. Frens, P. J. Lusse, M. R. Zuidda and E. J. Van der Drift: J. Electrochem. Soc. 148 (2001) C28

18) H. Tong, L. Zhu, M. N. Li and C. Wang: Electrochim. Acta 48 (2003) 2473-2477.

19) M. Y. Park, J. H. Son and S. W. Rhee: Electrochem. Solid State Lett. 1 (1998) 32-33.

20) D. K. Kwak, H. B. Lee, J. W. Han and S. W. Kang: Electrochem. Solid State Lett. 9 (2006) C171-C173.

21) O. Azzaroni, M. Fonticelli, P. L. Schilardi, G. Benítez, I. Caretti, J. M. Albella, R. Gago, L. Vázguez and R. C. Salvarezza: Nanotechnology 15 (2004) S197-S200.

22) M. F. Sharin, A. Razak and Z. Zainal: The Malaysian J. Appl. Sci. 11 (2007) 324-330.

23) A. V. Panin, A. R. Shugurov and K. V. Oskomov: Phys. Solid State 47 (2005) 2055-2059.

24) J. Yan, H. Takahashi, X. Gai, H. Harada, J. Tamaki and T. Kuriyagawa: Mater. Sci. Eng. A 423 (2006) 19-23.

25) H. Saka, A. Shimatani, M. Suganuma and M. Suprijadi: Philos. Mag. A 82 (2002) 1971-1981.

26) A. Kailer, Y. G. Gogotsi and K. G. Nickel: J. Appl. Phys. 81 (1997) 3057-3063.

27) G. Lucazeau and L. Abello: J. Mater. Res. 12 (1997) 2262-2273.

28) C. Lu, Y. W. Mai and Y. G. Shen: Key Eng. Mater. 312 (2006) 363368.

29) J. Thurm and R. F. Cook: J. Mater. Res. 17 (2002) 1143-1146.

30) Y. Cao, S. Allameh, D. Nankivil, S. Sethiaraj, T. Otiti and W. Soboyejo: Mater. Sci. Eng. A 427 (2006) 232-240.

31) D. Christopher, R. Smith and A. Richter: Nanotechnology 12 (2001) 372-383.

32) A. J. Leistner, A. C. Fischer-Cripps and J. M. Bennett: Proc. Int. Soc. Opt. Eng. (SPIE), Bellingharw, (5179 Optical Materials and Structures Technologies, 2003) pp. 215-222.

33) W. Soboyejo: Mechanical properties of Engineered Materials, (Marcel Dekker Inc., New York, 2003).

34) R. W. Olesinski, A. B. Gokhale and G. J. Abbaschina: Bull. Alloy Phase Diagrams 10 (1989) 635-640.

35) A. K. Saliana, M. Y. W. Mahmood, A. W. Zaidan, K. Anuar, M. N. Norkamizah, L. Y. C. Josephine and W. Y. W. Yusmawati: J. Solid St. Sci. Technol. Lett. 14 (2007) 105-112.

36) N. Brauner and M. Shacham: Chem. Eng. Process. 36 (1997) 243-249. 